https://revistas.unlp.edu.ar/TrayectoriasUniversitarias

Universidad Nacional de La Plata

La Plata | Buenos Aires | Argentina

\title{
Jóvenes científicos: aspiraciones, trayectorias e incertidumbres
}

Young scientists: aspirations, trajectories and uncertainties

Sosa, Águeda Marcela

https://orcid.org/0000-0003-1295-0137

sosa.marcela1@gmail.com

Universidad Nacional de Córdoba | Argentina

\section{RESUMEN}

El texto aborda reflexiones en torno a las incertidumbres que se presentan a los jóvenes científicos para el desarrollo académico y profesional. En particular -y a partir de una investigación que relaciona experiencias formativas y estilos académicos acerca de la formación de físicos en la UNC- en esta presentación nos centramos en rasgos de la trayectoria singular de un joven físico, que se desempeña en una institución estatal. Seleccionamos este caso por su fecundidad para el análisis de problemáticas más amplias de los campos universitario y científico en la actualidad.

\section{ABSTRACT}

The text addresses reflections on the uncertainties that are presented to young scientists for academic and professional development. In particular - and from an investigation that relates training experiences and academic styles about the training of physicists at the UNC - in this presentation we focus on features of the unique trajectory of a young physicist, who works in a state institution. We select this case for its fertility for the analysis of broader problems of the university and scientific fields today.

PALABRAS CLAVE trayectorias científicas, aspiraciones profesionales, experiencia formativa

KEY WORDS

scientific trajectories, professional aspirations, training experience 


\section{EXPERIENCIA FORMATIVA, ESTILOS ACADÉMICOS Y TRAYECTORIAS DIFERENCIADAS}

El presente trabajo es derivado de una investigación en la que abordamos la reconstrucción de la experiencia formativa de egresados en Física de la UNC, a partir del análisis de las formas en que ha sido modulada por los estilos académicos consolidados en la institucióni .

La interrogación nos llevó a identificar y relacionar los factores que han intervenido en esa construcción, abriendo también la pregunta sobre los modos en que se han perfilado experiencias diferenciales de los egresados, tanto de los considerados herederos (Bourdieu y Passeron, 2003), como de aquellos cuyos destinos profesionales y académicos se alejan de esa figura jerarquizada.

En esta presentación nos centramos en rasgos de la trayectoria singular de un joven físico $(\mathrm{HZ})$ que se desempeña en una institución estatal; y que integra un grupo mayor de egresados cuyo destino profesional fue configurado fuera de la facultad. En todos los casos, los relatos recogidos permiten trazar algunas líneas acerca de la realidad laboral de los físicos, la relación con la formación realizada y las demandas del mundo científico y tecnológico, en ámbitos estatales o privados.

\section{UNA TRAYECTORIA EN CRUCE ENTRE UNA ASPIRACIÓN Y UNA OFERTA DIFERENTE}

Se trata de la trayectoria de un egresado, para quien la demanda externa en una institución estatal lo llevó a modular un perfil profesional próximo a sus deseos iniciales: "trabajar en algo que tenga alguna relación con la sociedad". Este joven, quien sostuvo desde el inicio de la carrera una búsqueda clara, optó por la oferta de la facultad: "y caímos acá, nos dieron un folletito que decía, que se estudiaban un montón de fenómenos físicos que servían para esto, para lo otro (...) entonces, dije, ¡Listo!, esto está bueno (...) aprendo todos y después los aplico, así." Desde esta promesa, anunciada en un texto de difusión de las carreras, se inscribió en la Licenciatura.

\section{DE LA ESCUELA TÉCNICA A LA UNIVERSIDAD}

Con un grupo de sus compañeros de escuela secundaria técnica de una provincia del interior, se lanzaron a la búsqueda de una universi- 
dad y, luego de descartar la UBA, prefirieron explorar en universidades de provincia y llegaron a Córdoba, en donde tenían algún conocido. En este, como en otros casos, la primera opción no era Física, sino Ingeniería, carrera que desestimó por tener que cursar dibujo Técnico, una materia en la que había tenido dificultades para aprobar en el Secundario.

En este egresado, pudimos identificar ciertos rasgos tales como propensión al esfuerzo y la dedicación en pos de un objetivo, desplegando sus estrategias con criterios realistas, las que se traducen en una ajustada distribución del tiempo entre el estudio y el necesario trabajo; en compartir la vivienda con otros estudiantes, en suma, decisiones que favorecieron condiciones a pesar de no ser un estudiante de tiempo completo.

Durante los primeros tiempos de facultad, contaba con ahorros reunidos a través de diferentes trabajos eventuales durante el secundario, que permitieron su dedicación plena al estudio y que dan cuenta de estrategias de previsión para su sostén en la universidad.

Resultó llamativo comprobar que el cursado de primer año no lo sorprendió, "sabía lo que le esperaba", que la clave era el énfasis en Matemática, aunque sufrió el primer aplazo en Física I. A partir del tercer año, cuando los ahorros se terminaron, tuvo que trabajar, y eligió un empleo en un cyber de horario nocturno y atendiendo alumnos particulares, junto a la ayuda que llegaba de los esfuerzos familiares. Reconoce -a diferencia de otros entrevistados- que la asistencia a clase es importante y, en ese sentido, el trabajo fue un obstáculo: "sobre todo en los laboratorios, es fundamental (...) aunque debo haber rendido el $50 \%$ de las materias libre." (HZ)

Trabajar produjo demoras en rendir en el turno inmediato siguiente a las materias cursadas $y$, ante el reclamo de los profesores por su falta de presencia: "pero vos no estuviste en casi ninguna clase", y luego de rendir hasta cinco veces mal, para poder aprobar, finalmente recursaba. Observamos aquí la distancia con el cursado de aquellos becarios, quienes no debieron invertir el tiempo en trabajar, con mayores libertades para asistir o no a clases teóricas y con una inmersión total en la vida de la carrera.

\section{EL CURSADO DE LOS “DISCOORDINADOS"}

Para este egresado, la carrera duró diez años y en su relato esta demora obedece a la necesidad de recursar y de trabajar, cuestión que lo despega del grupo constituido al inicio, que brindaba referencias, acompañamiento y sostén. "Había un grupito que eran los discoordinados, digamos, los que no hacíamos la carrera en 6, 7 años (...) Nos encontrábamos en una y otra materia, nos juntábamos a estudiar, habíamos varios de esos" (HZ), es decir que el cursado irregular provocaba el armado continuo de nuevos grupos de acuerdo con los tiempos disponibles y las materias a rendir.

Esta situación aleja a la vez a los "discoordinados" de instancias de sociabilidad y amistad, tales como la participación en agrupaciones y en 
el centro de estudiantes, que también generan otros vínculos y solidaridades, y con otros ritmos. Es decir que, para algunos estudiantes, ciertas experiencias les están vedadas, aquellas que requieren tiempo y permanencia en la facultad: "no, porque no me daba el tiempo (...) no participo del grupo (...) conozco todo, había que dedicar tiempo y no" (HZ).

Esto lleva a interrogarnos en torno a cuáles son los sectores sociales dispuestos a la militancia estudiantil en la universidad y a la relación que puede establecerse entre las reinvindicaciones políticas y gremiales del sector, con las necesidades y expectativas de diferentes grupos de estudiantes.

Comprender el necesario esfuerzo para terminar la carrera y poder sostenerse en ello es una clave, saber que "si uno no es una mente brillante tiene que ponerle mucho sacrificio (...) y se agacha la cabeza y se va para adelante, hay que, no sé, creo que es una cuestión de personalidad también." (HZ)

El desaliento ante la no aprobación de los exámenes le hizo pensar en la posibilidad de salirse del juego, y en cambios de carrera "en esta época, cuando estaba rindiendo Mecánica y no aprobaba, iba a hacer una carrera que se había abierto hace muy poco en Salta que era Energías Renovables"; pero la confianza que le otorgó aprobar, finalmente, lo impulsó a seguir: "en ese envión de que aprobé Mecánica, aprobé como 3 más y, ya el número de materias que me quedaban acá era mucho menor a las que debía hacer allá". El desafío permanente era terminar lo iniciado, para poder finalmente buscar una inserción laboral.

\section{El desaliento ante la no aprobación de los exámenes le hizo pensar en la posibilidad de salirse del juego, y en cambios de carrera}

Ante nuestro interrogante acerca de la "dureza" de la carrera, la respuesta giró en torno a las modalidades de cada estudiante:

Hay personas y personas, algunos entenderán más rápido que otros las situaciones, a unos le costará más que otro (...) a mí me costaba bastante, sobre todo la parte que era totalmente teórica, y yo no podía bajar eso a una realidad concreta, digamos, terminaba aceptando todo y haciendo lo necesario para aprobar esa materia sin buscarle una realidad a lo que estaba viendo (...) si no, no avanzaba nunca, digamos. $(\mathrm{HZ})$

Este comentario abre a una cuestión muy interesante para el análisis del estudio en esta carrera, referido a la posibilidad de comprender abstracciones y procesos que no encuentran un correlato de materialidad concreta: "las cuánticas, Termodinámica II, Electro I, Electro II (...)” (HZ)

La estrategia desplegada para aprobar consistió en cierto ejercicio de alienación con respecto al modo en que se venía estudiando, es de- 
cir, para aprobar tuvo que aprender modos de resolución que fueron puestos en juego en el momento del examen, para luego, olvidar. Así es expresada esta forma de resolución frente a un obstáculo serio, que ponía en riesgo la culminación de la carrera:

A partir del tercer año, me cambié el chip de entender las cosas $100 \%$ a entender lo que me interesa y lo otro hacer lo necesario para aprobar esa materia, sino, no iba a terminar nunca, digamos. Al día de hoy, vos me preguntas algo de cuántica yo no me acuerdo absolutamente nada... sin embargo, las promocioné, o sea, porque en ese momento decidí esto, bueno esto es lo que me tengo que aprender, me lo aprendo, rindo, cumplo con lo que me están pidiendo iy adiós! (HZ)

Decimos alienación, porque se trataría de una estrategia que incluye aprender practicando intensamente y entender para alcanzar a resolver lo que se solicita y luego olvidar, sin conocer el sentido ni la aplicación de lo aprendido.

\section{EL APOYO DEL RECORDADO PROFESOR}

En general nuestros entrevistados recuerdan a determinados profesores: aquellos con buen trato, que explican bien en el desarrollo de las clases o de los prácticos. En este caso, $\mathrm{HZ}$ recuerda por el nombre, como a ningún otro, a aquel profesor que brindaba una modalidad de apoyo que atendía la particularidad del estudiante, es decir, el modo singular de entender y de pensar, su manera de resolver, y desde allí montaba su ayuda. Fue el único testimonio que encontramos de una ayuda individualizada, personal, que hace posible el logro mayor, aprobar.

\footnotetext{
"Electro II fue la última materia que rendí, no me acuerdo quién estaba en el teórico, pero estaba en el práctico Guille, que para mí, es uno de los mejores profes que tuve, sin duda, un tipo capaz de sentarse, escucharte, a vos y si se sientan dos, te escucha a vos y lo escucha a él y los dos preguntan por el mismo problema, pero te lo explica distinto a vos, que al otro, se da cuenta de que vos entendés de una manera y otro de otra manera...eh...y con toda la paciencia del mundo, digamos, así que para mí era re admirable (...) que tuve la suerte de tenerlo a él en esa última materia y aprobé". (HZ)
}

Estas capacidades docentes son las memorables, las que rompen la rutina del estudio y el cursado en soledad o en grupos eventuales, en las que se descubre interés y cuidado y, sobre todo, una particular sensibilidad a los procesos de aprendizaje individuales. 
Durante la conversación se deslizó la cuestión de las opciones que se presentaron al momento del egreso. Con respecto a la preeminencia de las lógicas de Conicet en las dinámicas institucionales, este egresado observa diferencias en el tiempo: "me parece que hay una generación ahora, que ya empezaba a abrir un poco más la cabeza y darse cuenta de que no era todo Conicet" (HZ), afirmando que las políticas de ciencia y técnica implementadas desde 2004 dieron chance a que diferentes instituciones soliciten físicos, amplíen sus recursos para el desarrollo de proyectos.

Durante los últimos años de cursado, comienza a conocer y entender el funcionamiento de las agencias de promoción y de desarrollo, reconociendo que tenía muy escasa información sobre la existencia de CONAE, CONEA, INTI, INVAP:

conocía poco, en todo lo que fue la carrera de grado las actividades de los físicos fuera de la facultad, poco y nada; yo empecé a darme cuenta de que, bueno, la cosa era muy cerrada, no, no había más opciones que seguir la carrera científica. (HZ)

Sin embargo, su idea de futuro tenía otros horizontes: "mi idea era conseguirme un trabajo y trabajar con algo, no tan aislado, digamos, no tanto de la publicación del paper y que ahí quedamos, no sé, era un vacío que no podía tapar con las manos" (HZ).

Al finalizar la carrera, se incorpora a un grupo de investigación y, en el marco de ese proyecto, se le otorga una beca Foncyt para la realización del doctorado. No obstante, se siente atraído por su idea primera y permanente, por los desarrollos aplicados por lo que se inscribe en la Maestría en Aplicaciones Espaciales de Alerta y Respuesta Temprana a Emergencias (AEARTE), en el Instituto Gullich de CONAEii: "se empezaban a ver cosas distintas" (HZ)

El cursado de la Maestría se realizó con beca completa financiada por CONAE y comprendió la estadía en una institución italiana asociada. La experiencia fue rica en múltiples aspectos, personales, sociales, académicos y laborales. La primera satisfacción fue sentirse seleccionado entre un grupo grande de aspirantes y, además, después de haber concluido los dos años del cursado, la posibilidad de seguir con un contrato de trabajo en CONAE.

Seguía siendo eterno becario, pero bueno (...) la maestría estuvo buena y costó un montón, no la maestría en sí, sino el abrir mi cabeza al estar sentado con compañeros que eran biólogos, que eran geógrafos, que eran de la parte ambiental, digamos, ninguno de una ciencia dura, así, y aprender a conversar con los otros, con los pares, 
en lenguajes totalmente distintos al que uno está acostumbrado, donde todo es mucho más cerrado, todo es mucho más encriptado, todo es distinto. $(\mathrm{HZ})$

Su primer aprendizaje allí fue el reconocimiento de otras realidades, saberes y lenguajes, a la vez que experimentar el desafío de atravesar este obstáculo y adaptarse.

\section{Su primer apren dizaje allí fue el reconocimiento de otras rea- lidades, saberes y lenguajes, a la vez que experimentar el de- safío de atravesar este obstáculo y adaptarse.}

Un ejercicio de exogamia, como plantea Carli (2012), que asimismo produce una cierta ruptura con creencias sobre la propia formación tanto como ratificación de haber transitado una formación de grado valiosa, por las capacidades que desarrolla: "aprendés que hay cosas afuera que vos no conocías y que uno creía que uno acá sabía todo lo que pasaba en el mundo y que uno era capaz de hacer todo, te das cuenta de que hay una diversidad de cosas que uno no sabe, que tiene por aprender". Una carrera considerada dura, pero que por eso mismo promueve la creencia de que "te podés adaptar a distintas cosas, te abre la cabeza para ser flexible". Además de la apertura a un mundo nuevo y poder medir las propias capacidades, la Maestría resultó un encuentro con la satisfacción de lo aplicado: en la realización de la tesis.

Terminé haciendo una cosa aplicada y con uso inmediato para otra gente, que era lo que era lo que yo estaba buscando (...) supongo que por eso me fue muy bien, porque le ponía muchas ganas, porque era lo que me gustaba en realidad y eso siguió y hoy es una línea base (...) estás sobre un problema real propio del país, de nuestra región, así que bueno, estoy super contento con eso [se ríe]

La estancia en Italia fue pródiga en nuevos lazos y pruebas, además de ser su primer viaje a Europa. La permanencia en un grupo conocido y muy unido, el cursado intensivo de más de ocho horas diarias de clases, la comunicación en un inglés muy técnico, rudimentario para la conversación, y del italiano aprendido rápidamente y en el contacto cotidiano, configuraron una experiencia de gran intensidad.

\section{ELTRABAJO ACTUAL: LA INSERCIÓN DE UN FÍSICO EN PROYECTOS MULTIDISCIPLINARES}

El Instituto Gullich es su ámbito actual de trabajo, en el que se desarrollan modelos para situaciones ambientales de riesgo, o información diversa. "Por un lado, la idea es modelado, para tener una idea de lo que va a pasar mañana o pasado, o distintos modelos para una semana, meses; por otro lado, un monitoreo, en tiempo real, y también en imágenes 
satelitales" (HZ), nos cuenta en referencia a líneas de trabajo y grupos en el instituto. La experiencia laboral se enriquece con el intercambio entre grupos e instituciones en los que se perfila un modo de hacer y pensar propio de la profesión:

Me costó, hay que flexibilizar para interactuar con los otros y eso fue lo más duro, para tratar de entender lo que él me está diciendo y que él entienda lo que yo le estoy diciendo (...) no lo puedo mandar a leer un libro de física a un biólogo para explicarle alguna cosa, bueno, me las tengo que arreglar y decirle, como pueda, qué es lo que le quiero explicar, qué le quiero hacer entender. $(\mathrm{HZ})$

Con respecto al valor del trabajo entre disciplinas, el entrevistado rescata la importancia de la participación y la interacción, y la necesidad de la presencia de todos con sus aportes específicos para la resolución de los problemas que se plantean. Nos explica con un ejemplo:

el tema de dengue, ahí hay físicos y hay biólogos, y lo usa la gente de medicina o los gobiernos (...) los físicos solos no podrían haber hecho nada sin saber las cosas del mosquito y la gente que estaba con el mosquito, no sabría cómo interpretar la temperatura del brillo de un satélite (...) es necesario tener todas las partes...que todas las partes estén involucradas para que lo que vos presentes como un producto final, tenga una coherencia para alguien. (HZ)

Su experiencia lo lleva a valorar, en perspectiva crítica, el funcionamiento de distintas entidades estatales y los procesos recientes de articulación y de mejoramiento en el uso de recursos que, por la fragmentación funcional y organizacional, no son aprovechados. Es decir que, en el trabajo, va ganando conocimiento y capacidades para el planteo de acciones que optimizan tareas y funciones.

\section{LA VALORACIÓN DE LA FORMACIÓN}

Nuestra indagación llevó a conversar acerca de necesidades de formación para el trabajo actual, vacíos en la propuesta académica que pudieran atenderse, así como logros en lo adquirido en la carrera:

\section{Nuestra indagación llevó a conversar acerca de necesidades de formación para el trabajo actual, vacíos en la propuesta académica que pudieran atenderse, así como logros en lo adquirido en la carrera:}


venga, digamos, un poder de análisis de lo que sea, por eso no me costó tanto adaptarme a esto que estoy haciendo ahora. Me parece que lo forman a uno para ser analítico en cualquier campo (...) Sin embargo, puedo criticar lo cerrado que ha sido siempre con respecto a la sociedad. (HZ)

En este sentido, con respecto a la producción en investigación, y más allá del valor intrínseco que pueda tener, le preocupa la responsabilidad en cuanto al uso de recursos y fondos asignados, por la rendición de cuentas a la sociedad. La apelación al compromiso social es una constante en las apreciaciones de este joven físico, y un ideario que ha guiado sus opciones.

\section{PERSPECTIVAS A FUTURO}

La transitoriedad del vínculo laboral actual, (de becario a planta transitoria), "yo diría incerteza", plantea las incertidumbres que se abren con relación a las políticas en ciencia y al mantenimiento de los proyectos iniciados en su institución. En este sentido, la tendencia en décadas anteriores favoreció a los becarios de Conicet, en tanto espacio que otorga mayor estabilidad o visto en otro sentido, de menor precariedad con respecto a las contrataciones eventuales, ligadas a programas cuyos destinos se presentan más vulnerables. Es en esta perspectiva, también, que hablamos en nuestra investigación de destinos diferenciales.

Nos detuvimos en este caso porque el itinerario delineado, deja ver procesos amplios referidos a las políticas nacionales en ciencia y tecnología en diferentes momentos, y con desarrollo desigual según los ámbitos. Destacamos el valor asignado a la formación de grado, en tanto capacidades desarrolladas transferibles en los nuevos requerimientos profesionales, y sus ausencias y saberes vacantes. Pero también consideramos las dificultades y sufrimientos personales por las que atravesaron los egresados antes, y atraviesan ahora, para transitar algunos tramos de la carrera, y la importancia de profesores memorables (Branda y Porta, 2012), para alcanzar su superación.

Una conclusión potente de éste y otros casos analizados, reside en la importancia de considerar a la formación universitaria como un proceso cuyos destinos se dirimen en las biografías escolares y sociales desde antes del ingreso a la vida universitaria, y que se trata de un conjunto de componentes en los que juega primordialmente el estilo académico dominante, con sus culturas y creencias, sus prácticas y relación con el conocimiento, en cruce con las condiciones de existencia de los grupos de estudiantes socialmente considerados. A lo que se sobreimprime, tal como plantea Beigel (2018) que la actual coalición gobernante, inició un proceso de ralentización de la expansión del sistema científico nacional, política que no solo se inspira en las necesidades del ajuste financiero, sino que además pretende reducir la gravitación de la educación y la ciencia públicas en Argentina. Consideraciones sobre una realidad que vuelve la mirada a otras épocas más oscuras y que nos interroga con respecto a los jóvenes, la universidad, la ciencia y el futuro. 
Beigel, F (2018). "Las relaciones de poder en la ciencia mundial. Un anti-ranking para conocer la ciencia producida en la periferia". Nueva Sociedad, No274, p.13-28.

Bourdieu, P. y Passeron, J. C. (2003). "Los herederos: Los estudiantes y la cultura". Buenos Aires: Siglo XXI Editores

Branda, S. A., y Porta, L. (2012). "Maestros que marcan. Biografía personal e identidad profesional en docentes memorables". Profesorado. Revista de currículum y formación del profesorado, V16 número 3. Universidad de Granada, España.

Carli, S (2012). "El viaje de conocimiento en las humanidades y las ciencias sociales. Un estudio de caso sobre profesores universitarios en la Argentina durante la segunda mitad del siglo XX". XVII Jornadas Argentinas de Historia de la Educación, UNTucuman.

Carli, S. (2012). “El estudiante universitario. Hacia una historia del presente de la educación pública". Buenos Aires: Siglo XXI Editores.

Sosa, M. (2016). "Estilos de trabajo académico y experiencia formativa". En Remedi, E. y Ramírez García, R. Los científicos y su quehacer. Perspectivas en los estudios sobre trayectorias, producciones y prácticas científicas. México: Anuies.

\section{NOTAS}

\footnotetext{
ísosa, M: Estilos académicos y experiencia formativa en la universidad. La formación de físicos en la UNC. Tesis de Doctorado en Ciencias Sociales. FCS-UBA.

ii El Instituto Gulich fue creado por la CONAE y la UNC /FAMAF en 2001 con el objetivo de formar recursos humanos capaces de realizar desarrollos de avanzada, aplicando tecnología e información de origen espacial.
} 